\title{
Executive Dysfunction among Children with Antipsychotic Treated Schizophrenia
}

\author{
Tjhin Wiguna ${ }^{1}$, Anthony Paul Sison Guerrero ${ }^{2}$, Shuji Honjo ${ }^{3}$, Irawati Ismail ${ }^{1}$, Noorhana Setyowati WR ${ }^{1}$, Fransiska \\ Kaligis ${ }^{1}$ \\ ${ }^{1}$ Child and Adolescent Psychiatry Division, Department of Psychiatry, University of Indonesia, Jakarta, Indonesia, ${ }^{2}$ Department of Psychiatry \\ and Pediatrics, University of Hawai'i John A. Burns School of Medicine, Honolulu, HI, USA, ${ }^{3}$ Department of Child Psychiatry, Center for \\ Developmental Clinical Psychology and Psychiatry, Nagoya, Japan
}

\begin{abstract}
Objective: To investigate the executive function among adolescents with antipsychotic-treated schizophrenia in Child and Adolescent Outpatient Clinic at Cipto Mangunkusumo General Hospital, Jakarta.

Methods: This was a cross sectional study with control group. Case was defined as adolescents with antipsychotic-treated schizophrenia without any mental retardation or other physical illnesses $(n=45)$. The control group consisted of healthy and age-matched adolescents ( $n=135$ ). Executive function is determined by using Indonesian version of Behavior Rating Inventory of Executive Function (BRIEF-Indonesian version). We used SPSS 16.0 program for windows to calculate the prevalence risk ratio (PRR) and set up the $p$ value $<0.05$.

Results: Mean of age was 16.27 (standard deviation 1.86) year-old. Most of the case group (95\%) has been treated with atypical antipsychotic such as risperidone, aripipripazole, olanzapine, and clozapine. Duration of having antipsychotic medication was ranged from one to 36 months. Adolescents with antipsychotic treated-schizophrenia had higher BRIEF T-score, except for inhibit scale, shift scale and behavior regulation index. The prevalence risk ratio on several clinical scales were higher in children with antipsychotic-treated schizophrenia compared to control group, such as on emotional state (PRR=7.43, 95\% confidence interval $[\mathrm{Cl}]=2.38-23.15$ ), initiate scale ( $\mathrm{PRR}=6.32,95 \% \mathrm{Cl}=2.51-15.95$ ), monitor scale ( $\mathrm{PRR}=8.11,95 \% \mathrm{Cl}=2.0-32.86$ ), and behavior regulation index ( $\mathrm{PRR}=4.09,95 \% \mathrm{Cl}=1.05-15.98)$.

Conclusion: In general, the results showed that adolescents with atypical antipsychotic treated-schizophrenia had higher BRIEF T-score compared, and comparable with their normal group control.
\end{abstract}

KEY WORDS: Childhood schizophrenia; Antipsychotics; Executive function; Indonesia.

\section{INTRODUCTION}

Schizophrenia among children and adolescents is a serious and devastating mental illness. While the exact etiology is not known, there are likely various genetic and psychosocial contributors. ${ }^{1-3)}$ There are several symptoms common to both adult and childhood schizophrenia; however, in the latter, the onset is earlier and the prognosis is poorer. Children and adolescents with schizophrenia often present with the insidious onset of auditory and visual hallucinations, flat or inappropriate affect, delusions, and a formal thought disorders. ${ }^{4-6)}$ At times, the signs and symp-

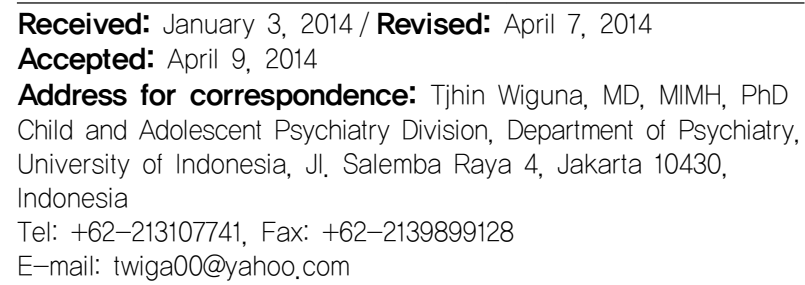

toms may be a challenge to distinguish from normal development. Children and adolescents with this disorder often have severe premorbid neurodevelopmental histories, neurobiological and cytogenetic abnormalities, stronger family history of mental illnesses compared to adult schizophrenia. ${ }^{7-9)}$

Childhood schizophrenia is a rare condition, with an estimated prevalence of 1 in 40,000. Very early onset schizophrenia (before age 13 years) is even rare, occurring in 1 in 500,000. By comparison, recent studies show that schizophrenia overall occurs in $1 \%$ of the world's population, irrespective of country and culture. ${ }^{10-12)}$

The neurodevelopmental abnormality in children with schizophrenia includes abnormalities in the amplitude and synchrony of oscillations during neural development, leading to cognitive deficits and psychotic symptoms. Specifically, Uhlhaas and Singer ${ }^{13)}$ revealed that childhood schizophrenia is associated with impaired synchronous oscillations during late brain maturation. Douaud et

(a) This is an Open-Access article distributed under the terms of the Creative Commons Attribution Non-Commercial License (http://creativecommons.org/licenses/by-nc/3.0) which permits unrestricted non-commercial use, distribution, and reproduction in any medium, provided the original work is properly cited. 
$a l .{ }^{14)}$ explained that children with schizophrenia had sensorimotor cortical and corticospinal tract structural abnormalities that remained stable over the period of observation. It is likely that understanding the mechanisms of childhood brain development may be key to the prevention and treatment of this disorder.

Children and adolescents with schizophrenia appeared to have reducing total brain volume, but this finding is not consistent across all studies. Several studies have found abnormalities in the shape and spatial location of the corpus callosum, caudate, and thalamus. Similar abnormalities are also observed in adult onset patients. Ventricular enlargement, reflecting progressive degenerative changes, appears in the brains of children with schizophrenia, but the degree of enlargement appears to reach an asymptote during young adulthood. ${ }^{15,16)}$

On formal testing, they generally demonstrate poor attention, processing speed, visual-motor and motor function, and executive function. ${ }^{17-21)}$ Executive function, through coordinating multiple, complex sub-processes in the brain through the frontal lobe, makes possible problem solving, response inhibition, strategy development and implementation, and working memory. ${ }^{17)}$ Therefore, children and adolescents with schizophrenia often have significant difficulties with tasks of daily functioning, including learning, socializing and self care. Hence, management of child and adolecent schizophrenia should include not only management of the hallucinations, delusions, and/or formal thought disorder, but also the improvement of cognitive and executive function and overall quality of life.

Antipsychotic medications such as haloperidol, trifluoperazine, risperidone, olanzapine, quetiapine, etc. sequentially bind onto different target receptors in the brain in a dose-dependent and concentration-dependent manner. All available anti-psychotics work by blocking the dop- amine-2 $\left(D_{2}\right)$ receptors to some extent, but differences in receptor binding affinities generally explain differences in the clinical profile of these drugs (in terms of clinical responses, side effects, etc.). ${ }^{22}$ Atypical antipsychotics work by more potent antagonism (compared to typical antipsychotics) toward serotonin-2A relative to $\mathrm{D}_{2}$ receptors (Table 1). ${ }^{22,23)}$

Nowadays, antipsychotic medications are widely used in treating children and adolescents with schizophrenia, and several randomized control trials have already been done for this population. ${ }^{24-26)}$ Several studies have shown that, compared to typical antipsychotics, atypical antipsychotics seem to have better effects towards executive function. $^{22-25)}$ Risperidone has demonstrated a consistently positive effect on working memory and executive function, while olanzapine appears to improve verbal learning and memory, verbal fluency, and executive function. $^{23)}$

The aim of this study was to identify the executive dysfunction among adolescents with antipsychotic treated-schizophrenia. The study assumed that there weren't any differences on executive function among adolescents with antipsychotic treated-schizophrenia compared to adolescents in control group.

\section{METHODS}

This was a cross sectional study with control group. Case group consisted of 45 adolescents from 12 to 18-years old with antipsychotic treated-schizophrenia seen at the Child and Adolescent Psychiatry (CAP) outpatient clinic Cipto Mangunkusumo General Hospital, Jakarta. They visited the CAP outpatient clinic between 2011 and 2012. The inclusion criteria consisted of parental consent to the study, while the exclusion criteria included mental retardation and other chronic physical illnesses.

Table 1. The potencies of antipsychotic medication toward receptor bindings (Ki values, nM)

\begin{tabular}{|c|c|c|c|c|c|c|c|}
\hline Antipsychotic & $\mathrm{D}_{2}$ & $5-\mathrm{HT}_{1 \mathrm{~A}}$ & $5-\mathrm{HT}_{2 \mathrm{~A}}$ & $5-\mathrm{HT}_{2 \mathrm{C}}$ & $a_{1}$ & $\mathrm{H}_{1}$ & $\mathrm{M}_{1}$ \\
\hline Risperidone & 3.3 & 210 & 0.2 & 25 & 2 & 58.8 & $>10.000$ \\
\hline Olanzapine & 11 & $>10.000$ & 4 & 23 & 19 & 7 & 1.9 \\
\hline Clozapine & 180 & 875 & 1.6 & 16 & 9 & 2.8 & 75 \\
\hline Quetiapine & 160 & 2,800 & 294 & 1,500 & 62.5 & 11 & 120 \\
\hline Aripiprazole & 3.4 & 1.7 & 3.4 & 15 & 57 & 61 & $>10.000$ \\
\hline $\mathrm{D}_{2}$ & \multirow{2}{*}{\multicolumn{7}{|c|}{$\begin{array}{l}\text { Extrapyramidal side effects, prolactin elevation } \\
\text { Hypotension }\end{array}$}} \\
\hline$\alpha_{1}$-Adrenergic & & & & & & & \\
\hline $\mathrm{H}_{1}$ & \multicolumn{7}{|c|}{ Sedation, weight gain, postural dizziness } \\
\hline$M_{1}$ & \multicolumn{7}{|c|}{ Deficits in memory and cognition, dry mouth, constipation, tachicardia, blurred vision, urinary retention } \\
\hline
\end{tabular}

D, dopamine; 5-HT, serotonin; $\alpha{ }_{1}$, alpha-1 norepinephrine; $H_{1}$, histamin; $M_{1}$, muscarinic acetylcholine-1.

Based on the article of Gardner et al. ${ }^{22)}$ (CMAJ 2005;172:1703-1716). 
Control group consisted of age-matched group adolescents $(n=135)$ but without any chronic medical or psychiatric illnesses, did not have any intellectual disability, no history of abuse. The research subjects of control group were selected by using the consecutive technique sampling, and obtained from the General Pediatric Clinic at Cipto Mangunkusumo General Hospital, Jakarta. We used the Mini Neuropsychiatric Interview (MINI) for kids to screen other mental disorders amongst both the study and control subject groups (Fig. 1). The protocol of this study has already been approved by the Ethic Committee from the Faculty of Medicine University of Indonesia.

\section{Instrument}

The executive function was assessed by using the Indonesian version of the Behavior-Rating Inventory of Executive Function (BRIEF-Indonesian version). BRIEF

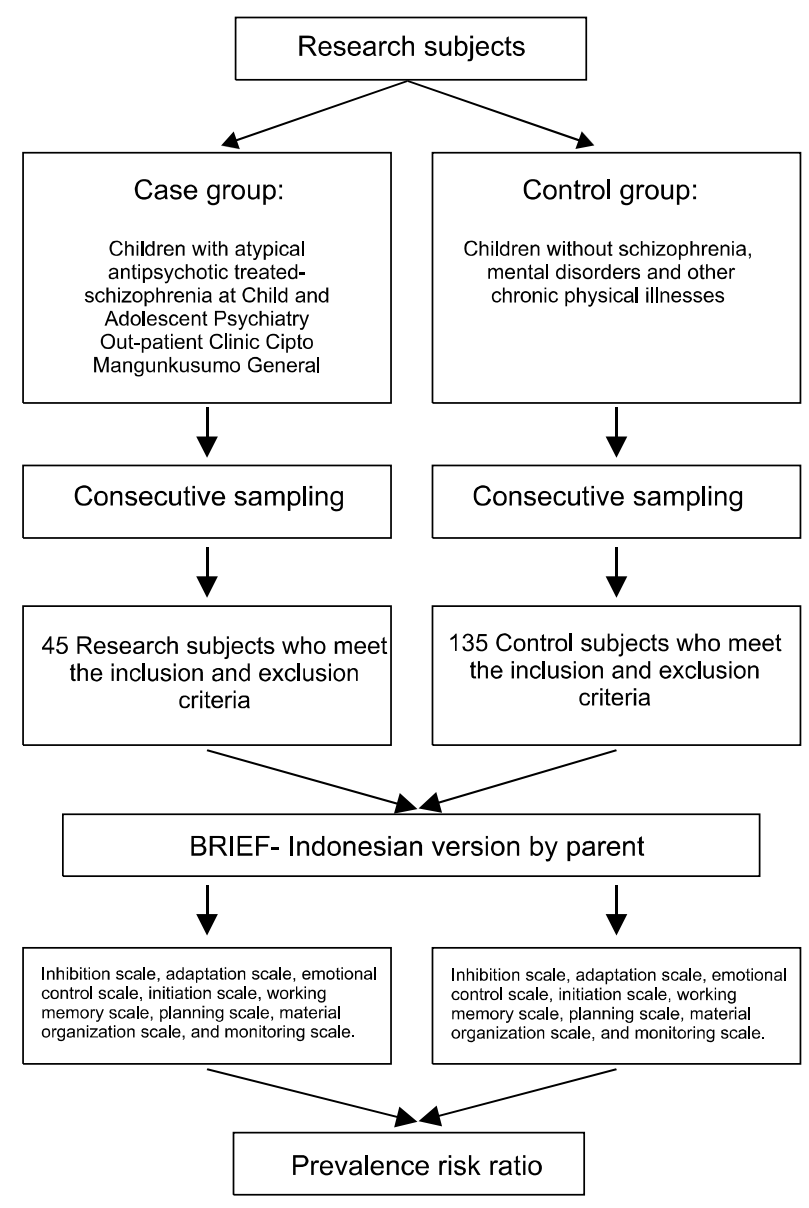

Fig. 1. The research pathway. BRIEF-Indonesian version: BehaviorRating Inventory of Executive Function, Indonesian version. An instrument to measure the executive function among children and adolescent rating by parents. was designed by Gerald A. Giogia and Peter K. Isquith in 2002 with the intent of evaluating executive function in children aged from 5-18 years by observing their daily behavior at home and at school. It includes a parent-completed questionnaire.

BRIEF has been validated into Indonesian language by the Department of Psychiatry, University of Indonesia. It consists of 86 statements, rated on a three-point likert scale $(1=$ never happened, $2=$ sometimes happened, $3=$ always happened) and organized in 8 clinical scales: inhibition, shift, emotional control, initiate, working memory, plan/organize, organization of material, and monitor scale. In addition to sub-scores in each of the domains, the BRIEF also yields summary index scores, including the Global Executive Composite, a summation from the 8 clinical scales; the Metacognition Index, a summation from initiate, working memory, plan/organize, monitor, and organization of material scales; and the Behavior Regulation Index (BRI), a summation from inhibit, shift, and emotional control scales.

The BRIEF raw data were converted into $T$-scores. The higher $T$-scores reflecting a disturbance in each domain of executive function. The BRIEF Indonesian version pointed the cut-off for $T$-scores was 65 to determine the executive dysfunction with $85 \%$ of sensitivity and $81 \%$ specificity. The BRIEF data in this study appeared to be valid and consistent, as the inconsistency level was less than 9 and the negativity level was less than 7 .

We also administered questionnaires to record socio-demographic information, weight $(\mathrm{kg})$ and height (cm) status, and the clinical global impression for improvement (CGI-I) scale.

\section{Statistical analysis}

We analyzed the data by using SPSS version 16.0 for Windows (SPSS Inc., Chicago, IL, USA). We applied the Kolmogorov-Smirnov normality test to characterize the normality of distribution of the data. Prevalence risk ratio (PRR) indicated as the prevalence probability of having dysfunction in the executive function among children with atypical antipsychotic treated-schizophrenia compared to the control group. We used $p<0.05$ as the point of value for statistical significant in this study.

\section{RESULTS}

The mean aged of research subjects either case or control group was 16.27 (standard deviation [SD] 1.86) years. All children with antipsychotic-treated schizophrenia 
continue their school and are described as having average class achievement nowadays.

Each child in case group only received one type of antipsychotic during the treatment course. Ninety five percent of the case group was treated by using atypical antipsychotic. The most prevalent atypical antipsychotic used was risperidone $(57.8 \%)$, and follow by aripiprazole, olanzapine and clozapine. Two children (5\%) with schizophrenia were treated by using trifluoperazine.

The duration of antipsychotic treatment ranged from one to 36 months, with the mean being 12.81 (SD 9.31)

Table 2. The characteristic of the research subjects $(n=180)$

\begin{tabular}{lcc}
\hline \multicolumn{1}{c}{ Characteristic } & $\begin{array}{c}\text { Case group } \\
(\mathrm{n}=45)\end{array}$ & $\begin{array}{c}\text { Control group } \\
(\mathrm{n}=135)\end{array}$ \\
\hline $\begin{array}{l}\text { Age (year) } \\
\text { Range }\end{array}$ & $11-18$ & $11-18$ \\
Mean \pm SD & $16.27 \pm 1.86$ & $16.27 \pm 1.86$ \\
Sex & $31(68.89)$ & $54(40.00)$ \\
Male & $14(31.11)$ & $81(60.00)$ \\
Female & & \\
Paternal ethnicity & $23(51.10)$ & $28(20.74)$ \\
Javanese & $7(15.55)$ & $34(25.19)$ \\
Sundanese & $1(2.22)$ & $5(3.70)$ \\
Minang & $3(6.67)$ & $1(0.74)$ \\
Bataknese & $11(24.44)$ & $64(47.41)$ \\
Betawinese & $0(0)$ & $4(2.96)$ \\
Others & & \\
Parental socioeconomic status & $24(53.33)$ & $113(87.70)$ \\
Low & $21(46.67)$ & $22(16.30)$ \\
Middle & & $12.39-31.00$ \\
Body mass index $\left(\mathrm{kg} / \mathrm{m}^{2}\right)$ & $21.87-35.20$ & $18.64 \pm 3.14$ \\
Range & $21.60 \pm 4.22$ & $p<0.05^{*}$ \\
Mean \pm SD & & \\
& &
\end{tabular}

Values are presented as range, mean \pm standard deviation (SD), or number (\%)

*By Mann-Whitney U-test. months. The CGI-I scale ranged from $1-6$, with $58 \%$ of subjects receiving scale between 3-4. Children with antipsychotic treated-schizophrenia had higher body mass indexes compared to the control group children although still in the normal ranged for both group. Most of the research subjects had a lower socioeconomic background (Table 2).

Children with antipsychotic treated-schizophrenia had significantly higher BRIEF $T$-scores on the emotional control, initiate, and monitor scale. On the other hand, they showed significantly lower $T$-scores for BRI (Table 3). Children with schizophrenia were at greater prevalent risk on emotional control (PRR 7.43, 95\% confidence interval [95\% CI] 2.38-23.15, $p<0.05)$, initiation of problem solving or activity (initiate scale; PRR 6.32, 95\% CI 2.51-15.95, $p<0.05$ ), and monitoring of own behavior (monitor scale; PRR 8.11, 95\% CI 2.00-32.86, $p<0.05$ ). They also demonstrated more prevalent to show problem in regulating their behavior (BRI; PRR 4.09, 95\% CI $1.05-15.98, p<0.05$ ) (Table 3).

\section{DISCUSSION}

Many studies showed children and adolescents with schizophrenia were at risk having disabilities towards their daily functioning. This condition was associated with brain development especially in the prefrontal and limbic cortex, which was ultimately affecting cognition, executive function and emotional control. The executive system theory explains that brain is the central coordinating system to regulating and guiding behavior from time to time in a constantly changing environment. ${ }^{27)}$ Various areas in the brain have been identified associating with the executive system such as the frontal, parietal, and occipi-

Table 3. Prevalence risk ratio (PRR) towards BRIEF domain $(n=180)$

\begin{tabular}{|c|c|c|c|c|c|}
\hline \multirow{2}{*}{ BRIEF domain } & \multicolumn{2}{|c|}{ T-score, mean (SD) } & \multirow{2}{*}{$p$-value* } & \multirow{2}{*}{ PRR } & \multirow{2}{*}{$95 \% \mathrm{Cl}$} \\
\hline & Case group & Control group & & & \\
\hline Inhibit scale & $44.98(1.02)$ & $48.49(8.30)$ & $>0.05$ & 0.50 & $0.14-1.78$ \\
\hline Shift scale & $45.33(1.36)$ & $48.55(1.05)$ & $>0.05$ & 1.04 & $0.46-2.36$ \\
\hline Emotional control scale & $44.44(1.35)$ & $43.07(8.55)$ & $<0.05$ & 7.43 & $2.38-23.15$ \\
\hline Behavioral Regulation Index & $44.38(9.93)$ & $45.93(7.17)$ & $<0.05$ & 4.09 & $1.05-15.98$ \\
\hline Initiate scale & $51.44(1.30)$ & $47.39(8.66)$ & $<0.05$ & 6.32 & $2.51-15.95$ \\
\hline Working memory scale & $40.73(7.50)$ & $38.87(6.54)$ & $>0.05$ & 1.34 & $1.23-1.46$ \\
\hline Plan/organize scale & $49.40(9.62)$ & $46.75(9.14)$ & $>0.05$ & 1.00 & $0.12-8.56$ \\
\hline Organization of materialsscale & $47.96(1.12)$ & $45.80(9.32)$ & $>0.05$ & 3.22 & $0.60-17.42$ \\
\hline Monitor scale & $47.04(1.05)$ & $43.65(8.81)$ & $<0.05$ & 8.11 & $2.00-32.86$ \\
\hline Metacognition index & $47.04(1.03)$ & 43.19 (8.59) & $>0.05$ & 2.81 & $0.89-8.86$ \\
\hline Global executive composite & $45.24(8.94)$ & $43.73(7.46)$ & $>0.05$ & 0.81 & $0.07-9.70$ \\
\hline
\end{tabular}

*By Mann Whitney U-test.

$\mathrm{SD}$, standard deiviation; $\mathrm{Cl}$, confidence interval. 
tal cortices, the thalamus and the cerebellum. ${ }^{28)}$

Antipsychotic medication could reduce the psychotic symptoms by bonding with dopamine, serotonin, norepinephrine, muscarinic, and cholinergic receptors, but it is still not clear enough whether they necessarily have the same beneficial effects on the overall brain development, cognitive and executive functioning specifically.

This study revealed that Indonesian children and adolescents with antipsychotic-treated schizophrenia demonstrated lower executive function in several domains compared to children in control group although they were still in normal ranged. In spite of having higher BRIEF $T$-score, they still could manage their daily functioning optimally. They can continue their school, keep their social interaction with their peer group and compete within their environment. They were more able to regulate their behavior and controlling their own impulse; they also could shift freely from one activity to another as the results of lower BRIEF $T$-score on the inhibition scale and shifting scale. In general they also had lower $T$-score on behavior regulation index, meant they could regulate their impulse better compared to children in the control group. This finding might be correlated with the effects of the antipsychotic on the dopaminergic and also serotonergic neurotransmitter in the mesolimbic-mesocortical pathway that could improve the behavior of the research subjects but further research need to be done. Overall, these findings increase the knowledge and understanding that using atypical antipsychotic gave a better outcome in children with schizophrenia.

On the other hand, the study findings would also explained that using atypical antipsychotic medication which has weaker potency on the muscarinic acetylcholine-1, glutamatergic, and cholinergic receptors give minimally effect on cognitive function in general and particularly on the executive function. ${ }^{29)}$ Other protective factors in our research subjects were normal intellectual functioning as reflected by their abilities to continue their study although there weren't any examination for the intellectual functioning and an active socialized pre-morbid adolescents. The above factors were good predictors for better outcome in childhood schizophrenia. ${ }^{30,31)}$

This study revealed that children and adolescents with antipsychotic-treated schizophrenia had higher PRR for emotional dysfunction, poor monitoring on their own emotional regulation and decreasing the initiative skills respectively. This was an interesting part that should be focused, because it showed that atypical antipsychotic solely could not improve the whole aspects of the cogni- tive and executive function. ${ }^{32,33)}$ Basically, they need other intervention approach and not only medications. Psychosocial interventions such as social skills training, cognitive remediation, anger management and also cognitive behavior therapy might help these children to overcome their boundaries.

There were several limitations of this study such as pre-morbid conditions only reported by parents, intellectual capacity examination and the course illness have not been analyzed thoroughly; information according to the previous cognitive training was not collected during the study; the length of antipsychotic used was not included in the analysis; the number of research subject with each type of antipsychotic medication was too small to be analyzed; not randomly selected due to the small number of children and adolescents with schizophrenia. On the contrary, this was the first study in Indonesia that tried to identify the executive function outcome of childhood schizophrenia treating by antipsychotic medication. This study also gave several positive feedbacks to family members such as good treatment outcome; stable daily functioning in post-treatment period, treatment compliance should be prioritized.

In conclusion, this study gave a clinical implication that using antipsychotic medication in treating childhood schizophrenia is very important for maintaining the executive function, but comprehensive management is the best in managing childhood schizophrenia.

\section{- Acknowledgments}

This study did not get any funding and there is no any conflict of interest.

\section{REFERENCES}

1. Kinros J, Reichenberg A, Frangou S. The neurodevelopmental theory of schizophrenia: evidence from studies of early onset cases. Isr J Psychiatry Relat Sci 2010;47:110117.

2. Kyriakopoulos M, Frangou S. Pathophysiology of early onset schizophrenia. Int Rev Psychiatry 2007;19:315-324.

3. Gejman PV, Sanders AR, Duan J. The role of genetics in the etiology of schizophrenia. Psychiatr Clin North Am 2010;33:35-66.

4. National Alliance on Mental Illness. Early onset schizophrenia. [cited 2013 July 12]. Available from: http://www. nami.org/Content/ContentGroups/Helpline1/Early_Onset_Sc hizophrenia.htm.

5. Rapoport JL. Childhood onset of "adult" psychopathology: clinical and research advances. Washington, DC:American Psychiatric Press Inc.;2000.

6. Asarnow RF, Nuechterlein KH, Fogelson D, Subotnik KL, Payne DA, Russell AT, et al. Schizophrenia and schizophrenia-spectrum personality disorders in the first-degree 
relatives of children with schizophrenia: the UCLA family study. Arch Gen Psychiatry 2001;58:581-588.

7. Kumra S, Shaw M, Merka P, Nakayama E, Augustin R. Childhood-onset schizophrenia: research update. Can $J$ Psychiatry 2001;46:923-930.

8. Nicolson R, Lenane M, Hamburger SD, Fernandez T, Bedwell J, Rapoport JL. Lessons from childhood-onset schizophrenia. Brain Res Brain Res Rev 2000;31:147-156.

9. Kumra S, Charles Schulz S. Editorial: Research progress in early-onset schizophrenia. Schizophr Bull 2008;34:15-17.

10. Remschmidt H. Schizophrenia in children and adolescents. In: Banaschewski T, Rohde LA, editors. Biological child psychiatry: Recent trends and developments. Basel, New York:Karger;2008. p.118-137.

11. Rapoport JL, Addington A, Frangou S. The neurodevelopmental model of schizophrenia: what can very early onset cases tell us? Curr Psychiatry Rep 2005;7:81-82.

12. Rapoport J, Chavez A, Greenstein D, Addington A, Gogtay N. Autism spectrum disorders and childhood-onset schizophrenia: clinical and biological contributions to a relation revisited. J Am Acad Child Adolesc Psychiatry 2009;48: 10-18.

13. Uhlhaas PJ, Singer W. The development of neural synchrony and large-scale cortical networks during adolescence: relevance for the pathophysiology of schizophrenia and neurodevelopmental hypothesis. Schizophr Bull 2011; 37:514-523.

14. Douaud G, Mackay C, Andersson J, James S, Quested D, Ray MK, et al. Schizophrenia delays and alters maturation of the brain in adolescence. Brain 2009;132:2437-2448.

15. Sowell ER, Toga AW, Asarnow R. Brain abnormalities observed in childhood-onset schizophrenia: a review of the structural magnetic resonance imaging literature. Ment Retard Dev Disabil Res Rev 2000;6:180-185.

16. Mehler C, Warnke A. Structural brain abnormalities specific to childhood-onset schizophrenia identified by neuroimaging techniques. J Neural Transm 2002;109:219-234.

17. Frangou S. Cognitive function in early onset schizophrenia: a selective review. Front Hum Neurosci 2010;3:79.

18. Kravariti E, Morris RG, Rabe-Hesketh S, Murray RM, Frangou S. The Maudsley early-onset schizophrenia study: cognitive function in adolescent-onset schizophrenia. Schizophr Res 2003;65:95-103.

19. Vourdas A, Pipe R, Corrigall R, Frangou S. Increased developmental deviance and premorbid dysfunction in early onset schizophrenia. Schizophr Res 2003;62:13-22.

20. Fuller R, Nopoulos P, Arndt S, O'Leary D, Ho BC, Andrea- sen NC. Longitudinal assessment of premorbid cognitive functioning in patients with schizophrenia through examination of standardized scholastic test performance. Am J Psychiatry 2002;159:1183-1189.

21. Rajji TK, Ismail Z, Mulsant BH. Age at onset and cognition in schizophrenia: meta-analysis. Br J Psychiatry 2009; 195:286-293.

22. Gardner DM, Baldessarini RJ, Waraich P. Modern antipsychotic drugs: a critical overview. CMAJ 2005;172: 1703-1711.

23. Meltzer HY, McGurk SR. The effects of clozapine, risperidone, and olanzapine on cognitive function in schizophrenia. Schizophr Bull 1999;25:233-255.

24. Masi G, Mucci M, Pari C. Children with schizophrenia: clinical picture and pharmacological treatment. CNS Drugs 2006;20:841-866.

25. Frazier JA, McClellan J, Findling RL, Vitiello B, Anderson $\mathrm{R}$, Zablotsky B, et al. Treatment of early-onset schizophrenia spectrum disorders (TEOSS): demographic and clinical characteristics. J Am Acad Child Adolesc Psychiatry 2007;46:979-988.

26. Kennedy E, Kumar A, Datta SS. Antipsychotic medication for childhood-onset schizophrenia. Schizophr Bull 2007; 33:1082-1083.

27. Robinson S, Goddard L, Dritschel B, Wisley M, Howlin P. Executive functions in children with Autism Spectrum Disorders. Brain Cogn 2009;71:362-368.

28. Jurado MB, Rosselli M. The elusive nature of executive functions: a review of our current understanding. Neuropsychol Rev 2007;17:213-233.

29. O'Grada C, Dinan T. Executive function in schizophrenia: what impact do antipsychotics have? Hum Psychopharmacol 2007;22:397-406.

30. Wozniak JR, Block EE, White T, Jensen JB, Schulz SC. Clinical and neurocognitive course in early-onset psychosis: a longitudinal study of adolescents with schizophreniaspectrum disorders. Early Interv Psychiatry 2008;2:169177.

31. Remschmidt H, Theisen F. Early-onset schizophrenia. Neuropsychobiology 2012;66:63-69.

32. Harvey PD, Napolitano JA, Mao L, Gharabawi G. Comparative effects of risperidone and olanzapine on cognition in elderly patients with schizophrenia or schizoaffective disorder. Int J Geriatr Psychiatry 2003;18:820-829.

33. McGurk SR, Lee MA, Jayathilake K, Meltzer HY. Cognitive effects of olanzapine treatment in schizophrenia. MedGenMed 2004;6:27. 